\title{
Development of the Russian tourism industry during the pandemic: an innovative approach
}

\author{
Elena Okhrimenko*, and Sergey Chernov \\ Ural State Economic University, 8 Marta str./People 's Volya, 62/45, 620144 Yekaterinburg, Russian \\ Federation
}

\begin{abstract}
The article deals with internal and external factors affecting the tourism industry in Russia as well as the ways of its promotion and development. The authors analyze decrease in sales in the tourism industry at the present period; the situation with provision of tourism services during the pandemic is identified and justified; the negative effects of the crisis are revealed. The authors also point out and present positive factors, which stimulate travel and tourism, including hotel business, catering, as well as resort business; the possibility of finding new ways to promote tourism industry is justified. The authors also analyze the main measures of tourism industry's state support. The article considers dominant areas affecting the development of domestic tourism. The authors assess main aspects contributing to the development of event tourism. Conditions for the development of sports and event tourism are investigated and discussed; special features of tourism industry stimulation during the pandemic are presented. The authors consider and justify the possibility of restoring the tourist market.
\end{abstract}

\section{Introduction}

Tourism is a highly developed economic sector. It is the tourism industry which has a huge impact on the development of the economy and brings the corresponding income to the country's budget. Tourism has a huge impact on such macroeconomic factors as employment, formation of gross domestic product, economic growth, etc. It is quite obvious that tourism industry has an effect on the following sectors of the economy: trade, communications, transport, catering, logistics and sales, information and computing services, etc.

Thus, it can be stated that tourism is becoming a catalyst for the country's socioeconomic development and sets the appropriate vector for the country's development.

\footnotetext{
*Corresponding author: oelenai@yandex.ru
} 


\section{Materials and Methods}

Many scientists have devoted their works to the study and analysis of issues related to the development of economic ties in the field of business tourism.

To date, not enough attention has been paid to research related to the development of domestic tourism and its impact on various sectors of national economy. In addition, in the context of the pandemic, the issue of reaching a new level of development of domestic tourism in the regions of this country remains relevant.

In this regard, it is necessary to mention the works by the scientists who have paid special attention to the peculiarities of domestic tourism and the identification of opportunities for its development.

The priorities in the field of development of domestic tourism and inbound tourism are considered in the works by T.N. Grigorenko, L.N. [4] Kazmina [4], D.R. Makeeva [7], E.V. Semenova [10] and others.

Russian tourism industry, its problems and prospects for its development are presented and substantiated in the works by V.I. Kruzhalina [6], N.V. Shabalina [6].

E. V. Fedorova believes that according to the Concept of the federal target program "Development of domestic and inbound tourism in the Russian Federation (2011-2016)", the priority area of development for Russia is business tourism. The creation of new enterprises and the improvement of existing ones in the sectors of economy, the level of economic development, the intensive introduction of foreign companies into the Russian market will affect the possible growth of business tourism in various cities and megalopolises [11].

The tourism industry generates good income and affects the country's economy. Now the Russian tourism, like tourism all over the world, is in a state of crisis. The emergence of the crisis is a consequence of the pandemic, which had a tremendous impact on almost all sectors of the economy. The government of the Russian Federation has provided the tourism industry with state support. But, despite all the negative impacts on the country's economy, positive aspects also should be mentioned. The sharp deterioration of the situation contributed to the working out of the new development measures and improvement of the industry as a whole.

It is important to discuss the factors affecting the development of tourism itself. The dominant factors include the following: the demographic situation in the country, geographical, political, legal and socio-economic factors.

Globally, special attention is paid to the study of such factors as scientific and technological processes, political stability and improving the quality of life since they also contribute to the further development of the tourism industry.

In many developed countries, tourism is the backbone of the economy. Paid holidays for employees form the basis of the market, both qualitatively and quantitatively. In the modern world, the role of business travel and travel of people of retirement age is enormous, because travel has become more accessible [13].

Analyses of the present state of tourism industry in Russia allows to consider its impact on the national economy.

The tourism industry was one of the first to be hit by the coronavirus infection. Firstly, citizens had to urgently return from foreign travel. Secondly, all current tours had to be interrupted, and the planned ones had to be postponed. In such a situation, absolutely all the participants of the tourist services market, including tour operators and carriers, had losses.

During the pandemic, there could be no question of any further development of the tourism industry, since the tourism business was under threat. According to experts and numerous studies, since the beginning of the pandemic, the demand for the most outbound destinations has decreased by $20-25 \%$, and after the closure of the borders it fell to 0 . 
Also, experts agree that such a crisis in tourism has not been observed since the Second World War [1].

The World Travel and Tourism Council (WTTC), which was held in early 2020, stated the fact that the pandemic had a negative impact on almost all areas of economy. First of all, special attention is paid to the world tourism market, where daily reduction up to a million jobs is observed. Germany, followed by Russia, is named the most affected country. The study says that losses due to the coronavirus on a global scale could be $\$ 2.1$ trillion.

According to Rosturizm, in Russia, the fall in sales in the tourism industry in the spring of 2020 reached almost $100 \%$. In addition, for the first half of the year, the total amount of lost income can amount to 1.5 trillion roubles.

In this situation, the main task is to develop measures to overcome the crisis [8].

The World Tourism Organization has offered its recommendations to mitigate the economic impact of the pandemic on tourism industry.

The document was developed with the participation of the World Health Organization (WHO), International Civil Aviation Association (ICAA), International Maritime Organization (IMO), Airports Council International (ACI), International Cruise Lines Association (CLIA), International Air Transport Association (IATA) and World Travel and Council Tourism (WTTC) [12].

The Government of the Russian Federation has provided the tourism industry with support.

Within the framework of state support, the following aspects have been identified: 6 months of deferral of tax payment and insurance contributions to state extra-budgetary funds; the dates for the start of tax audits have been postponed to a later period; the procedure for providing organizations with deferrals and instalments for the tax payment and insurance premiums for a period of up to one year has been simplified.

It is important to emphasize that tour operators received funds from the state in the amount of 3.5 billion roubles. These targeted funds should be used to pay tourists compensation for non-refundable tickets sold as part of tour packages.

Besides, gratuitous financial assistance from the state has been given to tourism industry as part of the anti-crisis measures of state support. The subjects of the tourism industry can use these funds to solve the most significant problems [9].

Despite all the negative consequences of the crisis, it is worth mentioning the positive aspects. After all, the current difficult situation has stimulated the tourism industry, hotel business, restaurant, as well as health resort sector, to find new ways of attracting customers. Also, staff and senior management discovered opportunities for working with clients online, developing new services. Trends of more active implementation of virtual and augmented reality technologies are going to be relevant for the future. At the same time, it is important to understand that customers' needs themselves will remain the same [3].

The pandemic will definitely change the service approach. Accommodation facilities will have to ensure high quality the service to attract and retain as many customers as possible.

It is important to pay special attention to sanitary safety. Hotels, health resorts and restaurants should be more careful in terms of cleaning and disinfection. At present this is extremely important, as people are worried about their health. People will give preference to the place where all prevention measures are taken.

It should also be noted that the demand for privacy has increased. Tourists want to be surrounded by those people who are close to them and to protect themselves as much as possible from the strangers who can tolerate the disease asymptomatically without knowing about it. 
At the moment it is very important to reorient people to internal directions. We need to launch advertising for the Russian resorts. Travel agencies should develop offer, and advertise as many tour packages as possible.

When will the tourist market recover? Hopefully, relatively quickly as people need positive emotions. Self-isolation, stress, and other factors have a negative effect on people' psycho-emotional state.

According to experts' most favorable forecasts, travel industry, hotel and resort sectors can recover by the fall of 2021. Less favorable forecasts indicate that everything will stabilize only by the fall of 2022. According to Forbes experts, changes in tourists' requests should be expected. Most likely, , people will more often choose weekend tours instead of long trips, and will go to nearby cities even to the countryside instead of foreign trips [2].

In the current situation of the pandemic, it is important to focus on the development of domestic tourism. In this regard, we concentrate on the development of event tourism in Russia.

It is necessary to say that within the framework of event tourism, various event activities can be considered. Event tourism remains relevant for any region of this country. In addition, event activities are the dominant component, as well as one of the fundamental resources for the development of the recreation and tourism industry in any region.

Events carried out at a high-quality level have a huge impact on the attractiveness of the region, help to bring tourists and cash flows. They are serve as the foundation for the development of domestic tourism in the region. Event tourism activates all spheres associated with tourism, it has a great economic effect on the region and the country as a whole. It should be noted that event tourism has a huge impact on the culture of the region, namely, there is a revival of traditions and customs, etc. It also influences the recognition of the region and the location where the events are held.

In our opinion, the development of sports and event tourism is the most promising direction and a very significant factor for the development of domestic tourism in the regions of this country, taking into account the current situation. It is known that sporting events are associated with mass entertainment. The role of sports is growing steadily. According to modern research, the share of sports and event tourism in the travel industry is increasing annually by $1.5 \%$. Consequently, sport remains a necessary part of a person's life.

Consumers of sports and event tourism actively attend sports events monitoring their holding in the regions of our country. Thanks to advertising, they get acquainted with hotels facilities (food, services, transport, service, the efficiency of using free time, etc.). it is important to pay special attention to ensuring the safety of absolutely all the participants of a sporting event. This requires resources and the adoption of appropriate security measures, taking into account modern requirements during the pandemic.

At present, it becomes quite obvious that regions should be interested in the development of sports and event tourism. In this regard, we will give an example of the development of the physical structure and sports basis of Yekaterinburg city.

Carrying out three strategic projects "Winter sports - second breath", "Stadium in the courtyard", "Sports Olympus" and the Municipal program "Development of physical culture and sports in municipal entity "city of Yekaterinburg" for 2017-2020" provide residents of Yekaterinburg with the opportunity to be systematically engaged in mass physical culture and sports and lead a healthy lifestyle is [5].

At the end of 2017 the number of sports facilities in Yekaterinburg increased by 98 units in comparison to the previous year and reached 2055 units. Today, sports facilities include urban infrastructure: sports grounds, bike paths, exercise facilities and seasonal skating rinks. The attendance capacity of sports facilities in 2017 amounted to 49,651 people per hour (in 2016 - 45,720 people per hour). 
In order to provide conditions for mass sports and an active lifestyle, as well as for preparation for the matches of the 2018 FIFA World Cup, the reconstruction of three sports grounds was completed: the Municipal Autonomous Institution "Sports Complex" Ural", the Municipal Autonomous Institution "Sports and recreation complex "Kalininets" and the Yekaterinburg municipal unitary enterprise "Park of the stadium Khimmash".

In 2017, 89 sports flat facilities were reconstructed in Yekaterinburg.

The level of development of the sports base allowed Yekaterinburg to become a platform for holding competitions of various levels. In 2017, 22 international competitions were organized (in comparison to 8 competitions in 2016) and 213 All-Russian competitions (228 competitions in 2016) [5].

Thus, the development of the physical infrastructure and sports basis in the regions has a huge impact on obtaining various kinds of benefits: social, cultural and economic.

Alongside with the benefits, issues related to further development of the region's infrastructure, construction of new sports facilities and hotels, increase in the flow of investments are considered. The role of sports in the growth of the region's prestige, an increase in the influx of tourists, which in its turn has a positive effect on replenishing the region's budget, cannot be overestimated.

It is important to understand that sports and event tourism and its development contribute to the increase in the spiritual and cultural level of the population, the formation of new views on the improvement of the body and promote a healthy lifestyle.

It is also necessary to take into account education of the population in the field of culture and history of the city and the rules of behavior in a multicultural environment, since our country is multi-confessional.

In our opinion, the integral feature for the development of sports and event tourism is, first of all, interregional cooperation in the field of tourism on mutually beneficial terms, especially during the pandemic. In fact, this aspect makes it possible to actively promote the national tourism product within the country, namely, between regions.

\section{Results and Discussion}

The relevance of the work lies in the fact that the proposed conclusions and a detailed analysis of the problems within the framework of the current state of the Russian tourism industry during the pandemic make it possible to pay special attention to the most significant characteristics of the development of domestic tourism. In addition, the analyses allow to take into account the benefits, including economic ones, which the development of sports and event tourism can bring for the regions and the country as a whole. The study identifies and substantiates the ways to promote the Russian tourism industry within the framework of the activities presented. All the designated events provide an opportunity to actively promote the national tourism product within the country, between regions, as well as opportunities to enter the international market when the situation with the pandemic stabilizes.

\section{Conclusions}

Current trends of the Russian tourism industry during the pandemic deserve special attention and thorough analysis in connection with the situation in the tourism market. First of all, it is necessary to identify the potential and substantiate the main ways of promoting tourism and travel industry in this country. In this regard, the development of domestic tourism provides tremendous opportunities for all regions. Therefore, active promotion of the national tourism product becomes obvious, especially during the pandemic. 
It is also necessary to emphasize that the development of domestic tourism, namely sports and event tourism, is impossible without the support of the state. The development of infrastructure has a positive effect on the prestige of the region, an increase in the tourist flow, and as a result, the budget replenishment.

In addition, the development of domestic tourism demand establishing strong mutually beneficial contacts between regions. It is important to find real opportunities and identify appropriate resources for the development of sports and event tourism in the regions of the country. As many people as possible must be convinced that there are numerous beautiful places in Russia, and most important, that the service in hotels and restaurants can be better than abroad.

A deeper and more detailed study of possible ways to promote the tourism industry in our country during the pandemic is necessary. Further research and its conclusions will foster regions development, budget replenishment and therefore improvement the quality of life and well-being of the Russian citizens.

\section{References}

1. In Russia, coronavirus can deprive more than a million people of work in the tourist industry, Daily electronic newspaper of the Russian Union of Travel Industry, https://ratanews.ru/

2. "In the future, domestic tourism." Tour operators talked about survival during the pandemic, https://fedpress-ru.turbopages.org/

3. Virtual travel will form delayed demand in tourism, Daily electronic newspaper of the Russian Union of Travel Industry, https://ratanews.ru/

4. T.N. Grigorenko, L.N. Kazmina, Bulletin of the National Academy of Tourism, 4, 14 (2015)

5. Results of the socio-economic development of the municipality "City of Yekaterinburg" in 2017, Department of Economics Administration of the city of Yekaterinburg, 156 (2018)

6. V.I. Kruzhalin, K.V. Kruzhalin, N.V. Shabalin, Bulletin of the National Academy of Tourism, 1, 10 (2016)

7. D.R. Makeeva, Issues of the regional economy, 1, 39 (2015)

8. Rostourism has developed a set of measures to save the industry, Daily electronic newspaper of the Russian Union of Travel Industry, https: //ratanews.ru/

9. The strategy for the development of tourism of the Russian Federation for the period until 2035, approved by Order of the Government of the Russian Federation of September 20, 2019 No. 2129-p, 50 , Government of Russia, http: //government.ru/

10. E.V. Semenova, N.V. Maslova, Bulletin of the National Academy of Tourism, 3, 34 (2016)

11. E. V. Fedorova, Management consulting, 4, 68 (2012)

12. UNWTO calls for support of the economy through the travel and tourism sector, Daily electronic newspaper of the Russian Union of Travel Industry, https://ratanews.ru/

13. Travel and Tourism Competitiveness Index, World Economic Forum, http: //reports.weforum.org/ 